\title{
Comparison of Absolute Intensities of [OI] 5577 in the Auroral and Subauroral Zones
}

\author{
F. E. Roach, J. W. McCaulley, and C. M. Purdy
}

(January 30, 1959)

\begin{abstract}
The distribution of 5577 zenith intensities is compared for Fritz Peak, Colo., in the subauroral zone and Thule, Greenland, near the geomagnetic pole. The absolute intensity is bright enough to permit visual detection at the Colorado station during 2 percent of the time and at the Greenland station, 27 percent of the time. The distribution curves have a general similarity, suggesting a phenomenological similarity in the excitation mechanisms at the two stations.
\end{abstract}

\section{Introduction}

In the preceding paper ${ }^{1}$ a discussion of [OI] 5577 zenith intensities in the subauroral region was given. In this contribution, some preliminary results are presented of measurements on the 5577 zenith intensity near the center of the auroral zone.

In October 1958, a photometer for the measurement of zenith intensities of 5577 was installed at Thule, Greenland, near the geomagnetic pole (geomagnetic latitude, $\Phi,=88^{\circ}$ ). Two telescopes were used, one with an interference filter centered on 5577 and the other on $5300 \mathrm{~A}$ for control. The instrument had been carefully calibrated against the airglow photometers at Fritz Peak (geomagnetic latitude $49^{\circ}$ ) before installation in Greenland so that it is possible to make a direct comparison of the absolute intensities at the two stations.

\section{Observational Data}

The hourly values of 5577 zenith intensities at Fritz Peak were chosen for 125 nights from July 1957 to September 1958, a total of 832 readings. During the first two months of operation at Thule, there were 16 nights of observation. In general, the intensities changed more rapidly than at Fritz Peak, and measurements of the records were made for each $1 / 4 \mathrm{hr}$, a total of 433 readings.

In table 1 are shown for the two stations, the direct and cumulative distributions of intensities according to 50-rayleigh class intervals up to 1,000 rayleighs (R).

In figure 1, the percent occurrence versus intensity is shown for both stations. In figure 2, the same data are shown with a logarithmic abscissa. In table 3 , some of the statistical results are summarized.

\section{Discussion}

The following empirical facts are noted: (1) The occurrence $(27 \%)$ of intensities greater than the visual threshold $(\approx 1,000 \mathrm{R})$ is in substantial agreement with the results of visual auroral observations $(20 \%)$ according to Vestine ${ }^{2}$; (2) there is no gap between the intensities conventionally referred to as

\footnotetext{
F-1 F. E. Roach, J. W. McCaulley, and E. Marovich, The origin of [OI] 5577 in the airglow and the aurora, J. Research NBS 63D, (1959)

2 E. H. Vestine, The geographic incidence of aurora and magnetic disturbance, northern hemisphere, Terrestrial Magnetism and Atmospheric Elec. 49, 77 (1944),
}

TABLE 1. Distribution of zenith intensities to the visual threshold

\begin{tabular}{|c|c|c|c|c|}
\hline \multirow{2}{*}{ Class interval } & \multicolumn{2}{|c|}{ Fritz Peak } & \multicolumn{2}{|c|}{ Thule } \\
\hline & By interval & Cumulative & By interval & Cumulative \\
\hline $\begin{array}{l}\quad R \\
0 \text { to } 49 \\
50 \text { to } 99 \\
100 \text { to } 149 \\
150 \text { to } 199 \\
200 \text { to } 249\end{array}$ & $\begin{array}{r}\% \\
0.1 \\
.2 \\
1.3 \\
7.0 \\
10.7\end{array}$ & $\begin{array}{rr}\% & \\
& 0.1 \\
.3 \\
1.6 \\
8.6 \\
19.3\end{array}$ & $\%$ & $\%$ \\
\hline $\begin{array}{l}250 \text { to } 299 \\
300 \text { to } 349 \\
350 \text { to } 399 \\
400 \text { to } 449 \\
450 \text { to } 499\end{array}$ & $\begin{array}{r}11.7 \\
12.9 \\
11.3 \\
10.1 \\
8.7\end{array}$ & $\begin{array}{l}31.0 \\
43.9 \\
55.2 \\
65.3 \\
74.0\end{array}$ & $\begin{array}{l}1.2 \\
3.0 \\
5.5\end{array}$ & $\begin{array}{l}1.2 \\
4.2 \\
9.7\end{array}$ \\
\hline $\begin{array}{l}500 \text { to } 549 \\
550 \text { to } 599 \\
600 \text { to } 649 \\
650 \text { to } 699 \\
700 \text { to } 749\end{array}$ & $\begin{array}{l}6.6 \\
4.6 \\
4.4 \\
2.4 \\
1.9\end{array}$ & $\begin{array}{l}80.6 \\
85.2 \\
89.6 \\
92.0 \\
93.9\end{array}$ & $\begin{array}{l}9.7 \\
6.5 \\
8.5 \\
9.9 \\
8.3\end{array}$ & $\begin{array}{l}19.4 \\
25.9 \\
34.4 \\
44.3 \\
52.6\end{array}$ \\
\hline $\begin{array}{l}750 \text { to } 799 \\
800 \text { to } 849 \\
850 \text { to } 899 \\
900 \text { to } 949 \\
950 \text { to } 999 \\
\text { A bove } 999\end{array}$ & $\begin{array}{r}1.2 \\
0.8 \\
.8 \\
.5 \\
.4 \\
2.4\end{array}$ & $\begin{array}{r}95.1 \\
95.9 \\
96.7 \\
97.2 \\
97.6 \\
100.0\end{array}$ & $\begin{array}{r}7.4 \\
3.7 \\
3.9 \\
2.1 \\
3.0 \\
27.3\end{array}$ & $\begin{array}{r}60.0 \\
63.7 \\
67.6 \\
69.7 \\
72.7 \\
100.0\end{array}$ \\
\hline
\end{tabular}

TABLE 2. Distribution of zenith intensities brighter than the visual threshold (Thule)

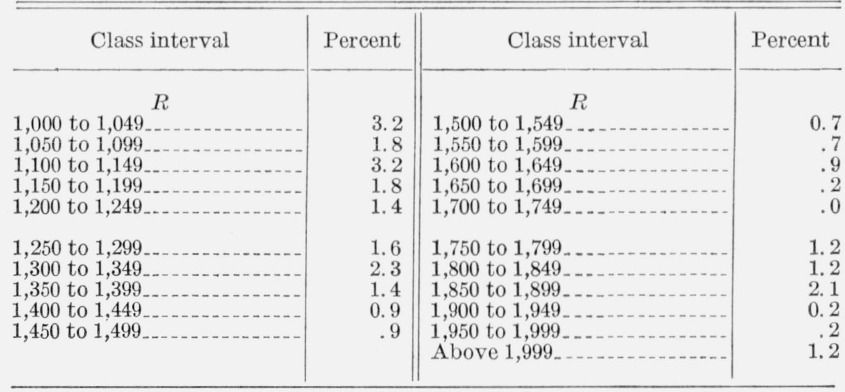

TABLE 3. Summary of statistical results

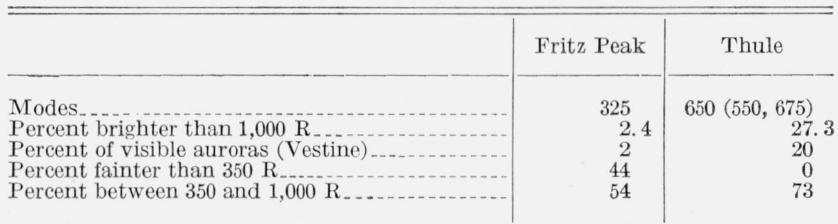

airglow $(Q<1,000 \mathrm{R})$ and those of an Aurora I $(1,000 \mathrm{R}<Q<10,000 \mathrm{R})$; and (3) the distribution curves for the two observing stations are similar in 


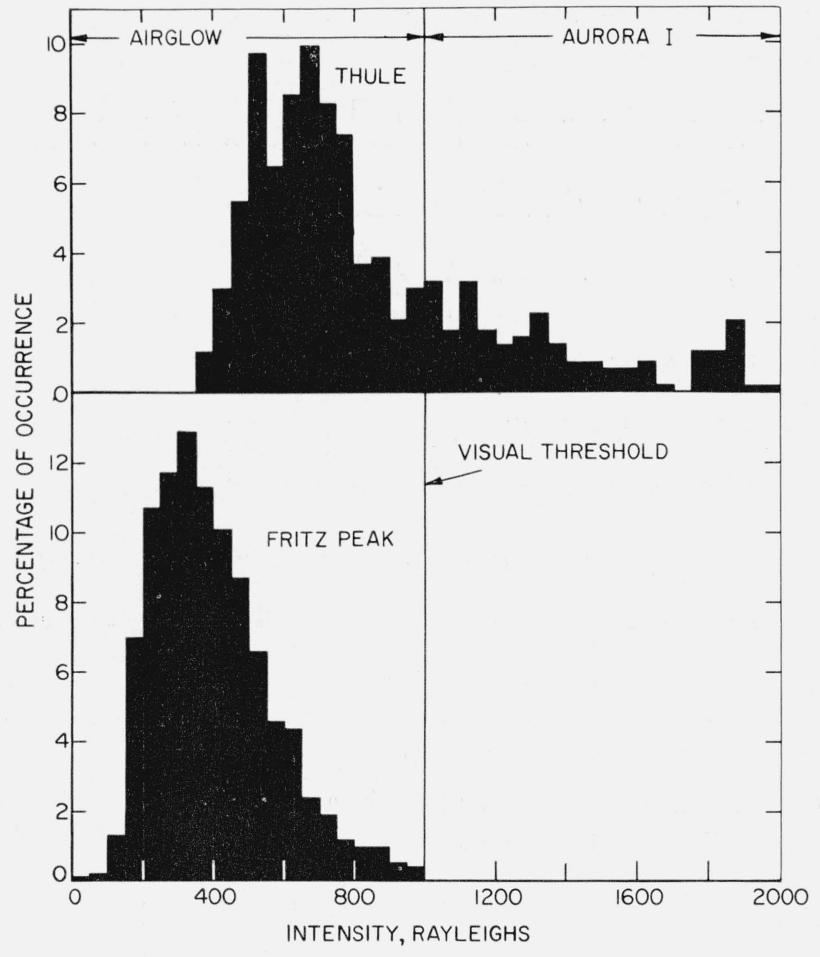

FIGURE 1. Histograms showing distribution of $55 \% \mathrm{y}$ zenith intensities (linear scale) at Thule and Fritz Peak.

appearance, roughly, but not exactly, as though the intensities at Thule were twice those at Fritz Peak.

Is there any evidence for a phenomenological distinction between the 5577 airglow $(0<Q<1,000$ $\mathrm{R})$ and the 5577 Aurora I $(1,000 \mathrm{R}<Q<10,000 \mathrm{R})$ ? The question is pertinent because of the fact that the visual threshold $(Q \approx 1,000 \mathrm{R}$ in the green) is the distinction by definition between the 5577 airglow and an aurora with International Brightness Coefficient I. A widespread assumption is inherent in the current literature that the two phenomena are separate and distinct with different mechanisms responsible for the airglow (photochemical reactions) and the aurora (solar-terrestrial streams).

The evidence of this paper does not support the conjecture that the two phenomena are distinct but, rather, strongly suggests that a common physical mechanism should be sought for both.

The data so far accumulated do not give any information on the brighter Auroras II $(10,000$ $\mathrm{R}<Q<100,000 \quad \mathrm{R}=100 \mathrm{kR})$, III $(100 \mathrm{kR}<Q$ $<1,000 \mathrm{kR})$, and IV $(Q>1,000 \mathrm{kR})$, since none was observed of these intensities during the period of study. Near the auroral zone where auroras are reported nightly, it should be possible to determine (1) whether there is any evidence for a statistical distinction between Auroras I, II, III, or IV, or (2) whether for each station there is a distribution similar to those found for Fritz Peak and Thule. Probably the only published paper that bears on the question is that of Currie ${ }^{3}$ who made visual

3 B. W. Currie, Night sky brightness at latitude $52^{\circ}$, Trans. Am. Geophys. Union 31, $539(1950)$

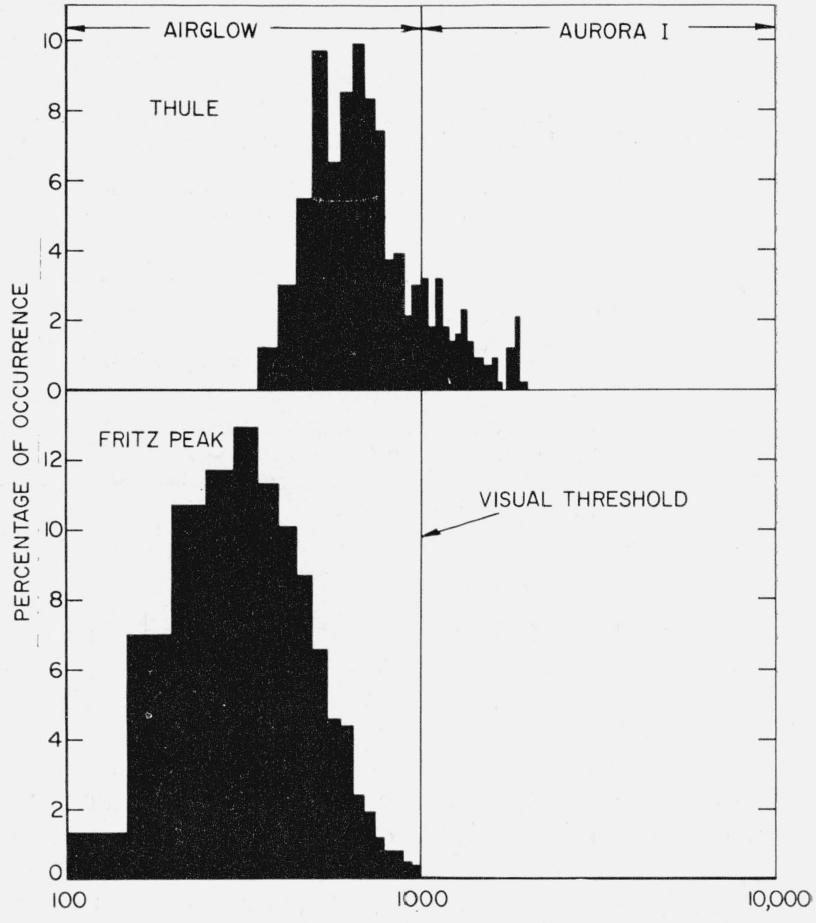

INTENSITY, RAYLEIGHS

Figure 2. Histograms showing distribution of $55 \%$ y zenith intensities (logarithmic scale) at Thule and Fritz Peak.

observations at Saskatoon $\left(\Phi=60^{\circ} .5\right)$ with a Hulburt ${ }^{4}$ photometer. According to Vestine's study, the auroral occurrence should be almost the same at Saskatoon as at Thule. It is of interest to note (table 4) that the zenith intensity observed by Currie was also on the average about twice that of subauroral regions, in agreement with present results from Thule and Fritz Peak.

TABLE 4. Comparison of visual observations at Saskatoon and midlatitudes

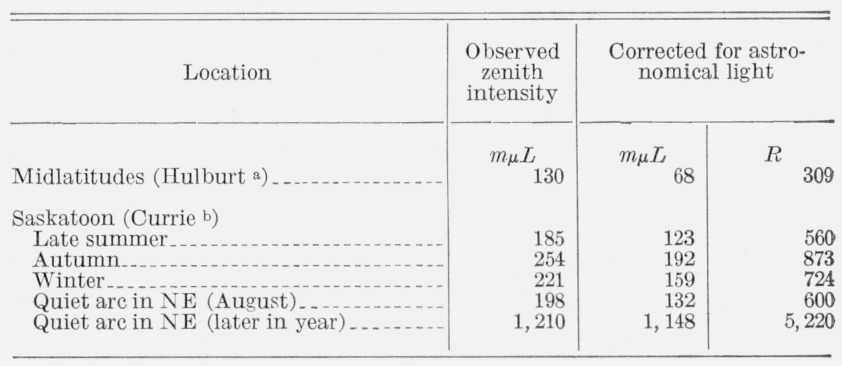

a See footnote 4 .

b See footnote 3 .

The authors are deeply indebted to the Air Force Cambridge Research Center (Bedford, Mass.) personnel of which installed and operated the photometer at the Thule station. The personnel actively engaged in the operation were Maj. John B. MacWherter, 2d Lt. Don Smart, M. Sgt. John W. Hubin, and A2c Frank Pavlica, Jr.

\footnotetext{
${ }^{4}$ E. O. Hulburt, Survey of the brightness of the night sky, NRL Report N-3263 (1948)
}

Boulder, Colo. (Paper 63D1-3). 